\section{AB1378-HPR EFFECT OF CLINICAL CHARACTERISTICS, HABITS, PHYSICAL ACTIVITY LEVELS AND FUNCTIONAL CAPACITY ON QUALITY OF LIFE IN SYSTEMIC SCLEROSIS PATIENTS}

Hazal Yakut ${ }^{1}$, Sevgi Özalevli ${ }^{1}$, Ahmet Merih Birlik ${ }^{2} .{ }^{1}$ Dokuz Eyll niversite Fizik Tedavi ve Rehabilitasyon Yksek Okulu, İmir, Turkey, ${ }^{2}$ Dokuz Eyll niversitesi Hastanesi, Immunoloji-Romatoloji Anabilim dalı, Izmir, Turkey

Background: In patients with Systemic sclerosis (SSc), many factors such as inactivity, smoking, gastrointestinal system involvement are reported to have an adverse effect on overall health related quality of life, and quality of life is in line with the prognosis of the disease $(1,2)$.

Objectives: The aim of this study was to investigate the effect of clinical characteristics, habits, physical activity levels and functional capacity of patients with SSc on quality of life.

Methods: Twenty-tree SSc patients were included in the study. The ages of patients, the amount of cigarette consumption, duration of diagnosis and body mass indexes (BMI) were questioned and recorded. Functional capacities of patients were measured by 6 Minute Walking Test (6MWT). Physical activity levels of patients were calculated using the International Physical Activity Questionnaire (IPAQ; using metabolic equivalent-MET). Quality of life was evaluated by the short form SF-36 quality of life questionnaire(SF-36 QoLQ). The SF-36 questionnaire was evaluated as two sub-scales, physical and mental.

Results: The mean age of the patients was 51.0011 .10 years and the duration of diagnosis was 7.604 .80 years, BMl was $26.606 .37 \mathrm{~kg} / \mathrm{m}^{2}$ and amount of cigarette consumption was 6.023 .30 packetyears. The mean physical activity levels (IPAQ) were 281.6860.45 MET, 6MWT distance were 435.3980.45 m, SF-36 QoLQ-physical were 32.4813 .42 and SF-36 QoLQ-mental were 38.5611 .42 score. It was found that there was a significant correlation between SF-36 QoLQ-physical and BMI ( $p=0.043, r$ $=-0.426)$, 6DWT $(p<0.001, r=0.737)$ and IPAQ $(p=0.001, r=0.647)$. There was a significant correlation between the SF-36 QoLQ-mental and 6MWT $(p=0.020, r=0.483)$ and IPAQ $(p=0.002, r=0.614)$.

Conclusion: Reduced levels of physical activity in SSc patients affect functional capacity. Reduced physical activity level and functional capacity decrease the quality of life of patients related to both physical and mental health. Physical health related quality of life of patients is negatively affected by the increase in BMI. Functional capacity, clinical characteristics, habits and physical activity levels should be evaluated and improved in treatment programs aimed at improving the overall health-related quality of life of patients.

\section{REFERENCES}

[1] Turesson, C., \& Matteson, E. L. (2007). Cardiovascular risk factors, fitness and physical activity in rheumatic diseases. Current Opinion in Rheumatology, 19(2), 190196.

[2] Hudson, M., Thombs, B. D., Steele, R., Panopalis, P., Newton, E., Baron, M., \& Canadian Scleroderma Research Group (2009). Health related quality of life in systemic sclerosis: A systematicreview.ArthritisandRheumatism,61(8),11121120. https://doi.org/10.1002/art.24676

Disclosure of Interests: None declared DOI: 10.1136/annrheumdis-2019-eular.2659

\section{AB1379-HPR EFFECTS OF DIFFERENT EXERCISE MODELS ON PAIN FUNCTIONALITY, BALANCE, PROPRIOCEPTION AND COGNITION FEATURES OF PATIENTS DIAGNOSED WITH FIBROMYALGIA}

Hadi Yavuz ${ }^{1}$, Türker Şahinkaya ${ }^{2}$, Ayşegül Ketenci ${ }^{1}$, Gökhan Metin ${ }^{3} .{ }^{1}$ Istanbul University, Physical Medicine and Rehabilitation, Istanbul, Turkey, ${ }^{2}$ Istanbul University, Sports Medicine, Istanbul, Turkey, ${ }^{3}$ Istanbul University-Cerrahpasa, Physiology, Istanbul, Turkey

Background: Fibromyalgia syndrome (FMS) is a chronic disease characterized by diffuse pain, fatigue, sleep disturbance, cognitive impairment, and other physical symptoms that adversely affect physical and sensory functions and impair quality of life. Nowadays, in the treatment of FMS, low intensity aerobic exercises and exercise programs combined with other treatment methods are recommended.

Objectives: The aim of this study was to evaluate the effects of aerobic and balance-proprioception exercises on the symptoms of Fibromyalgia (FMS) and the superiority of the two exercise models.
Methods: 51 female patients who adhere to the inclusion criteria were divided into two groups randomly. Aerobic Exercise Group (AEG; $n=26$ ) and Balance-Proprioceptive Exercise Group (BPEG; $n=25$ ) was applied to the exercise laboratory under the supervision of physiotherapist in Istanbul Medical Faculty, Department of Sports Medicine 3 days a week for 6 weeks. Before and after the program Pain (VAS), functional status (FIQ), postural stability (Biodex balance system), knee joint proprioception (Cybex isokinetic dynamometer) were evaluated. Cognitive status was assessed by Standardized Mini Mental State Examination (SMMSE) only before program.

Results: There wasnt statistically significant difference between demographic (age, weigh, BMl etc.) and clinic (VAS, FIO, Biodex, Cybex, SMMSE) features of the groups at the beginning $(p>0.05)$. Parameters measured in both groups after exercise programs showed progress com pared to initial levels $(p<0.05)$. There aren`t superiority between two exercise groups in terms of VAS, FIQ scores $(p>0.05)$. Recovery is found to be superior at BPEG in balance parameters (eyes open overall stability index (EOOSI) and eyes open anterioposterior stability index (EOAPSI)) and some parameters that belongs to proprioception $(p<0.05)$.

Conclusion: It is determined that aerobic exercise and balance-proprioception exercise programs at/in FMS are effective -in positive way- methods for functionality, pain, proprioception and balance parameter recovery of the patients. Except EOOSI and EOAPSI balance parameter values; according to other parameters it is found that aerobic exercise and balance-proprioception exercises are equal to each other. It is found out that balance-proprioception exercises are superior to aerobic exercises for improving EOOSI and EOAPSI. It is revealed that balance proprioception exercises are more effective for curing proprioception. It is observed that patients with FMS had deterioration in cognitive functions.

\section{REFERENCES}

[1] Duruturk N, Tuzun EH, Culhaoglu B. Is balance exercise training as effective as aerobic exercise training in fibromyalgia syndrome? Rheumatology international. 2015;35(5):845-54.

[2] Kibar S, Yıldız HE, Ay S, Evcik D, Ergin ES. New approach in fibromyalgia exercise program: a preliminary study regarding the effectiveness of balance training. Archives of physical medicine and rehabilitation. 2015;96 (9):1576-82.

Disclosure of Interests: None declared

DOI: 10.1136/annrheumdis-2019-eular.5682

\section{AB1379B-HPR PATIENT SATISFACTION IS HIGH IN PATIENTS TRAINED TO SELF-INJECT WITH A BUTTON FREE AUTO-INJECTION USING VIDEO TRAINING}

Dawn Homer. Modality Partnership Community Rheumatology Service, Enki Medical Practice, Birmingham, United Kingdom

Background: Once-weekly subcutaneous injection of methotrexate can optimize long-term treatment of rheumatic diseases such as rheumatoid arthritis. ${ }^{1}$ However, available self-injection devices vary in terms of ease of use and level of operational dexterity required.

Objectives: This pilot study compared patient satisfaction with use of a methotrexate pre-filled, button-free, auto-injector pen (Nordic Pharma, UK) for subcutaneous injection with previous use of a button-activated pen device following the option to self-train via video.

Methods: Patients with rheumatoid arthritis currently administering subcutaneous methotrexate using a button-activated pen device were invited to change to a button-free auto-injector by letter. They were given the option to self-train using an online video or receive one-to-one instruction from a rheumatology nurse. Initial follow-up took place immediately after the first injection; invitation to participate in a 10-minute telephone questionnaire to evaluate their experience of using their new device took place after 3-4 weeks. Satisfaction with the device was assessed overall and according to 7 specific autoinjector attributes: ease of injection; experience of injection; comfort in hand; use with dexterity issues or during flare-ups; confidence in full dose being given; convenience of storage and disposal; and portability.

Results: Thirty-three patients were invited to change to an auto-injector: 22 patients responded (response rate: 64.7\%), 19 of which made the switch and completed the survey. $79 \%$ of patients overall were satisfied or very satisfied with administering methotrexate using the auto-injector $85 \%$ of patients were equally or more satisfied with the use of an autoinjector pen compared to their previous device. Patients were equally or 
more satisfied with the new device across all 7 autoinjector attributes: convenience of storage and disposal (100.0\%), portability (100.0\%); comfort in the hand $(94.1 \%)$; confidence in full dose being given $(88.9 \%)$; use with dexterity issues or during flare-ups (85.7\%); ease of injection $(82.4 \%)$; experience of injection $(68.4 \%)$. Self-training via video did not negatively affect satisfaction: $83.3 \%$ of those patients confident in their ability to perform self-injection correctly after viewing the video were satisfied or very satisfied with their new autoinjector device. Three patients discontinued with the new device: one switched to oral therapy for reasons unrelated to the device; two returned to their original device.

Conclusion: This pilot study showed that patients were more satisfied with use of a methotrexate button-free auto-injector device than with their previous auto-injector device across all 7 user attributes and that satisfaction was maintained with use of self-training. Patient views regarding acceptability and use of auto-injection devices should be considered when making device switches based on cost and nurse resource allocation to ensure continued adherence with injected medication.

\section{REFERENCES}

[1] Bianchi B, et al. Methotrexate and Rheumatoid Arthritis: Current Evidence Regarding Subcutaneous Versus Oral Routes of Administration. Adv Ther 2016;33:36978.

Disclosure of Interests: Dawn Homer Grant/research support from: This project was supported by an unrestricted educational grant from Nordic Pharma., Consultant for: Participation in an advisory board with JanssenCilag in 2018 and will be speaking for Roche-Chugai in March 2019. DOI: 10.1136/annrheumdis-2019-eular.5764

\section{HPR Measuring health (development and measurement properties of PROs, tests, devices)_}

\section{AB1380-HPR THE EFFECTS OF CERVICAL RANGE OF MOTION ON POSTURAL STABILITY IN PATIENTS WITH CHRONIC NECK PAIN}

Onur Aydogdu ${ }^{1}$, Gülşah Kılıç ${ }^{1}$, Tolga Taşbaş ${ }^{1}$, Zübeyir Sarı ${ }^{1} .{ }^{1}$ Marmara University, Faculty of Health Sciences, Department of Physiotherapy and Rehabilitation, Istanbul, Turkey

Background: Neck pain is a common musculoskeletal problem within chronic pain and it effectuates up to $71 \%$ of adult population during their life time (1). Chronic neck pain is related to a series of disabilities: a range of reported pain, postural stability problems, and cognitive dysfunction (2). However, there is no report that investigate the relationship between range of motion and postural stability in patients with chronic neck pain.

Objectives: The purpose of this study was to investigate the effects of limitations in cervical range of motion on postural stability in patients with chronic neck pain. We hypothesized that the patients who have extension limitation might have postural stability deficit with flexion direction.

Methods: Thirty subjects of mean age $28.50 \pm 10.95$ years who admitted with chronic neck pain to a Private Physiotherapy Clinic were participated in this study. While goniometer was used for cervical range of motion, pedalo sensamove system was used for postural stability. In addition, pain and disability were measured with visual analogue scale, neck disability index, respectively.

Results: It was found that limitation of cervical range of motion was not correlated to postural stability deficits $(p>0.05)$. The neck pain and disability status was not associated with level of postural stability $(p>0.05)$.

Conclusion: The findings of this study showed that postural stability may not be affected by the limitation of cervical range of motion, and also neck pain intensity, neck disability status in patients with chronic neck pain. Further research with larger sample sizes is warranted.

\section{REFERENCES}

[1] Demirbüken I, Özgül B, Kuru Colak T, Aydoğdu O, Sarı Z, Yurdalan SU. Kinesiophobia in relation to physical activity in chronic neck pain. J Back Musculoskelet Rehabil. 2016;29(1):41-7.

[2] Nazari G, Bobos P, Billis E, MacDermid JC. Cervical flexor muscle training reduces pain, anxiety, and depression levels in patients with chronic neck pain by a clinically important amount: A prospective cohort study. Physiother Res Int. 2018 Jul;23(3):e1712.

Disclosure of Interests: None declared

DOI: 10.1136/annrheumdis-2019-eular.7538

\section{AB1381-HPR ADAPTABILITY, EFFECTIVENESS AND SAFETY OF TOFACITINIB IN PATIENTS WITH RHEUMATOID ARTHRITIS}

Fernando Rodriguez ${ }^{1}$, Anggie Aza $^{2}$, Michael Cabrera ${ }^{3}$, Pedro Santos-Moreno ${ }^{4}$, Diana Buitrago-Garcia ${ }^{5}{ }^{1}$ Biomab - Center for rheumatoid arthritis, Patient program coordinator, Bogotá, Colombia; ${ }^{2}$ Biomab - Center for rheumatoid arthritis, Bussiness administration, Bogotá, Colombia; ${ }^{3}$ Biomab - Center for rheumatoid arthritis, EHR administration, Bogotá, Colombia; ${ }^{4}$ Biomab - Center for rheumatoid arthritis, Rheumatology, Bogotá, Colombia; ${ }^{5}$ Biomab - Center for rheumatoid arthritis, Nursing research, Bogotá, Colombia

Background: Tofacitinib is a, selective JAK inhibitor that preferentially inhibits Janus kinase (JAK) 1 and JAK3. Oral tofacitinib $5 \mathrm{mg}$ twice daily or $11 \mathrm{mg}$ once daily is indicated for the treatment of moderate to severe active rheumatoid arthritis (RA) in adult patients who have responded inadequately to, or who are intolerant of, one or more DMARDs. Mainly, one of the strengths of Tofacitinib, is that it is a very suitable medicine for those patients who are afraid of applying a parenteral biological medicine, or who are of advanced age or are at high risk of adverse events, therefore It's easy to discontinue it.

Objectives: We aim to describe the tolerance and adaptability of patients to Tofacitinib, as well as the effectiveness and safety in patients with RA in a real-life setting in Bogotá, Colombia.

Methods: During 2017 and 2018 we followed-up patients from a RA specialized center in Colombia receiving Tofacitinib. Patients were treated with therapeutic goals type T2T and a multidisciplinary approach. Clinical follow-up was designed by the authors according to DAS28 as follows: every $3-5$ weeks (DAS28 > 5.1), every $7-9$ weeks (DAS28 $\geq 3.1$ and $\leq$ 5.1 ), and every $11-13$ weeks (DAS28 < 3.1). Tender joint count (TJC), swollen joint count (SJC) and DAS28 were measured on each visit. Therapy had to be adjusted with DAS28 > 3.2; We divided patients in four groups: remission (REM), low disease activity (LDA), moderate disease activity (MDA) and high disease activity (HDA) patients and one aim of the study was to look at what percentage of patients who were in moderate or severe disease activity reached a low disease activity or remission. On the other hand, we evaluated the tolerance and adaptability of patients to Tofacitinib. Adverse events were classified according the Common Terminology Criteria for Adverse Events (CTCAE) of the World Health Organization. Descriptive epidemiology for continuous variables, measure of central tendency and dispersion for qualitative and categorical variables through percentages and averages were calculated.

Results: We included 59 patients receiving tofacitinib, 92\% were women and $8 \%$ men during last two years. Mean age was 6011 . From total, $70 \%$ of patients received anti-TNF drugs before tofacitinib and the other $30 \%$. In reference to the adaptability, most of the patients up to $95 \%$ expressed to be happy with the oral intake and the suitable dosage of the medication. Regarding effectiveness, mean DAS28 at beginning was 4.6 0.83 and at the end 2.60 .63 ; At the beginning of follow-up $57.6 \%$ of patients were in moderate disease activity according to DAS28 and $33.9 \%$ in severe disease activity, while at the end of follow up $64 \%$ of patients achieved remission and $16.9 \%$ low disease activity during the 12 months of follow-up. See table 1. Regarding safety 2 patients presented a dermatological adverse event (herpes zoster) with adverse event rate of $3.3 \%$.

\begin{tabular}{lcccc}
\hline \multirow{2}{*}{ ACTIVITY LEVEL } & \multicolumn{2}{c}{ BASELINE } & \multicolumn{2}{c}{24 MONTH FOLLOW-UP } \\
\cline { 2 - 5 } & $n$ & $\%$ & $n$ & $\%$ \\
\hline REM & 5 & 8.47 & 38 & 64.41 \\
LDA & 34 & 57.63 & 10 & 16.95 \\
MDA & 20 & 33.90 & 0 & 18.64 \\
HDA & &
\end{tabular}

Abstract AB1381HPR Table 1. DAS28 in patients receiving tofacitinib.

Conclusion: Tofacitinib is a very suitable medicine in patients with RA and improved disease activity in impressive way; also proved to be very safe, except the occurrences of herpes zoster, which is an aspect to take into account in its prescription, but none of patients presented another serious adverse events.

Disclosure of Interests: Fernando Rodriguez: None declared, Anggie Aza: None declared, Michael Cabrera: None declared, Pedro Santos-Moreno Grant/research support from: $\mathrm{Dr}$ Santos has received research grants from Janssen, Abbvie and UCB, Speakers bureau: $\mathrm{Dr}$ Santos has received speaker fees from Sanofi, Lilly, Bristol, Pfizer, Abbvie, Janssen and UCB, Diana Buitrago-Garcia: None declared DOI: 10.1136/annrheumdis-2019-eular.7456 